\title{
Maureen C. Miller, Clothing the Clergy. Virtue and Power in Medieval Europe (c. 800 - 1200)
}

Ithaca, Cornell University Press, 2014, 286 p.

\section{Alain Rauwel}

\section{(2) OpenEdition}

\section{Journals}

Édition électronique

URL : http://journals.openedition.org/assr/28374

DOI : $10.4000 /$ assr.28374

ISSN : $1777-5825$

\section{Éditeur}

Éditions de l'EHESS

Édition imprimée

Date de publication : 31 décembre 2016

Pagination : 360

ISSN : 0335-5985

Référence électronique

Alain Rauwel, « Maureen C. Miller, Clothing the Clergy. Virtue and Power in Medieval Europe (c. 800 -

1200) », Archives de sciences sociales des religions [En ligne], 176 | octobre-décembre 2016, mis en ligne le 05 septembre 2017, consulté le 23 septembre 2020. URL : http://journals.openedition.org/assr/ 28374 ; DOI : https://doi.org/10.4000/assr.28374

Ce document a été généré automatiquement le 23 septembre 2020.

(c) Archives de sciences sociales des religions 


\section{Maureen C. Miller, Clothing the Clergy. Virtue and Power in Medieval Europe (c. 800 - 1200)}

Ithaca, Cornell University Press, 2014, 286 p.

\section{Alain Rauwel}

\section{RÉFÉRENCE}

Maureen C. Miller, Clothing the Clergy.

1 La paramentique, discipline ecclésiologiquement importante en ce qu'elle permet l'identification visuelle des clercs, si elle est assez bien étudiée pour les périodes récentes, a longtemps souffert pour les siècles pré-tridentins de n'être quasiment pratiquée que par des techniciens de laboratoire, décrivant longuement et avec un profit médiocre pour l'historien les procédures de sauvetage d'objets certes rares et fragiles. Il était grand temps qu'une recherche plus ambitieuse lui fût consacrée, un siècle après les travaux fondateurs de Joseph Braun. On ne peut que se réjouir qu'elle paraisse aujourd'hui sous la signature de Maureen Miller, une médiéviste particulièrement chevronnée qui se meut avec une parfaite aisance dans les nombreux domaines connexes dont son sujet lui impose la fréquentation.

2 L'auteur pose d'abord la distinction entre les ornements liturgiques à proprement parler, ceux que les différents ordres du clergé revêtent pour la célébration du culte public, et le costume courant des ecclésiastiques, que l'anglais permet d'appeler joliment « clerical street-wear ». C'est là une césure essentielle que la littérature, Miller incluse, ne marque généralement pas assez. Les champs d'étude sont pourtant bien différents, et leurs implications diverses. La liturgie est hétérotopique, elle se déroule sur une autre scène (et dans une autre temporalité) que les actes du quotidien; son fonctionnement n'est certes pas déconnecté des structures sociales globales, mais il les exprime selon des modalités spécifiques. L'auteur analyse ces modalités dans son 
chapitre 2, qui est probablement le meilleur de l'ouvrage. Elle y montre comment, dans les rites d'ordination, l'imposition des insignes textiles était un véritable acte constitutif ; comment, jour après jour, la signification morale des ornements était rappelée par des textes spécifiques récités privatim avant le culte, les prières de vêture ; comment, dans les bibliothèques, les commentaires liturgiques développaient et raffinaient ces interprétations par la méthode allégorique. L'auteur brille ici par un optimisme excessif : elle voit les évêques, des Carolingiens au XIII ${ }^{e}$ siècle, rédiger leurs expositiones pour l'éducation de l'ensemble de leur clergé, une éducation qui aurait selon elle commencé, pour les jeunes clergeons confiés aux églises, par «un long internat liturgique » : c'est faire du cas des cadets de l'aristocratie placés dans les riches chapitres des cathédrales une règle générale, à laquelle pourtant l'immense majorité du bas clergé rural échappait totalement.

Cette difficulté est récurrente dans l'étude de Miller : des ornements portés par "le » clergé médiéval nous ne savons pour ainsi dire rien. Nous connaissons un peu, par les trésors et les ouvertures de tombes, le vestiaire des prélats, papes, évêques, dignitaires, ce qui est tout autre chose. De même, les représentations mosaïquées, peintes ou sculptées, sur lesquelles l'auteur fait grand fond, ne montrent qu'eux - et selon quelles procédures? Il est périlleux de comparer une chasuble préservée (après combien de reprises et réfections?) et une chasuble figurée sur une image commémorative. La grammaire propre de l'image, à commencer par le jeu des couleurs, ici capital, introduit des biais dont on peut penser qu'ils ne sont pas assez soulignés. C'est donc sous toutes réserves qu'il faut enregistrer le changement que repère l'auteur à partir du milieu du IX siècle, passage selon elle d'un «style sobre » à un "style orné ». L'expression ellemême n'est pas forcément du meilleur aloi, renvoyant plutôt aux taxinomies de la rhétorique ou de l'art ancien. Dans l'économie de l'ouvrage, elle sert à décrire l'adoption en paramentique de matériaux précieux, soie et or, dont le but serait de marquer sensiblement une forme d'association des prélats aux princes dans le gouvernement de la société chrétienne, selon la logique des concessions inventées au $\mathrm{VIII}^{\mathrm{e}}$ siècle dans la pseudo-donation de Constantin. Il est bien vrai que l'assimilation fréquente des pièces du vestiaire sacré à des armes pour le combat spirituel légitime tout à fait, par exemple, le parallèle proposé entre les sceaux du chevalier armé et de l'évêque paré. Mais l'auteur, qui avait fort bien noté précédemment la force du modèle vétéro-testamentaire du Temple, néglige quelque peu ce filon lorsqu'elle suggère une lecture plutôt « théologico-politique » des ornements ottoniens ou grégoriens. La figure paradigmatique d'Aaron n'entre pas en scène au IX siècle, mais dès Grégoire le Grand et sa Regula pastoralis, voire plus tôt. On ne suivra donc pas l'auteur sans réticence sur une voie qui la conduit à proposer des raccourcis comme "pontifical regalia", dont on redoute qu'ils résistent mal à l'analyse précise.

Plus original est le chapitre IV, dans lequel sont introduites des actrices nouvelles: les femmes. L'auteur montre comment, lorsqu'on connait les conditions d'exécution des aubes ou des chasubles, ce sont toujours des mains féminines que l'on trouve à l'œuvre. Les filles d'Éve, à qui le rituel interdisait toute proximité avec les lieux du sacré, ne contournaient-elles pas l'obstacle en préparant et réparant les tissus destinés à la célébration? Ne se rendaient-elles pas symboliquement présentes à l'autel, lorsqu'il s'agissait d'abbesses ou de princesses, en brodant leur nom sur les ornements? Vêtements d'hommes, mains de femmes: espace de négociation et de circulation. Espace d'intériorisation aussi, suggère l'auteur, en faisant siennes les conclusions de 
recherches psychologiques sur le rôle de ce que l'on porte dans l'assimilation de comportements et de rôles sociaux. Du coup, on retient volontiers sa proposition de lire le vestiaire liturgique comme un vecteur important des idéaux réformateurs, entre $\mathrm{XI}^{\mathrm{e}}$ et $\mathrm{XII}^{\mathrm{e}}$ siècles: unifiant le corps clérical, marquant les hiérarchies en son sein, permettant la réception extra-discursive d'un ethos de la distinction, les textiles conquièrent leur place au premier rang des objets dont la manipulation est indispensable au fonctionnement de la machine sociale. L'avoir montré avec érudition et délicatesse suffit à inscrire le beau livre de Maureen Miller parmi les classiques des ritual studies. 